\title{
Gender Differences in Communication Patterns of Females in Single-Sex and Mixed-Sex Schools in Nnewi Education Zone
}

\author{
Nwosu, Eucharia Nchedo \& Joachim C. Omeje
}

\begin{abstract}
This study examined gender differences in communication patterns of females in single-sex and mixed-sex schools. The design of the study was an ex-post facto design. Two research questions and one hypothesis guided the study. All the population of 218 senior secondary II female students was used for the study which is an indication that no sampling technique was adopted. Data for the study were collected using a checklist. To analyse the data collected, frequency tables, percentage and chi-square were used. The result showed that the dominant communication patterns of females in single-sex school include appropriate gestures, correct grammar, fluency, staying on topic, talkativeness, politeness, use of no slang, loudness, emotionality, use of no tag questions and cooperative/supportive attributes. The same is applicable in mixed sex school, but with a slight difference in the area of soft spokenness. The result of the hypothesis revealed that school-type influences female students communication patterns significantly which implies that the communication patters of a female student sometimes depends on whether she is in a single-sex school or mixed sex school. Based on the findings, recommendations were made.
\end{abstract}

\section{Introduction}

Research into gender and communication has generated much controversy amongst sociologists within the field of sociology of education. At the heart of these controversies, remains the issue of explaining the process of communication between males and females and to assess how it differs from the same sex communication; and to suggest as to the explanations for the differences. Simply researchers 
want to know how things work, why they speak and work the way they do.

What then is the meaning of gender? Gender is a social and cultural constructs which describes roles, status, expectation, relationship and obligations for males and females based on their biological make up (Keller, 1991). According to Azikiwe (2001) gender implies social and historical constructs for masculine and feminine roles, behaviours, attributes and ideologies, which connote some notion of biological sex. According to Pollard and Morgan (2002:601) "gender refers to socially constructed expectation for male and female behaviour which prescribe a division of labour and responsibilities between males and females which grant different rights and obligations to them".

Gender differences in communication are often the source of much frustration and anger between males and females, and this difference is as a result of the socialization process of the individual. According to Tannen (1993), males are socialized to see the social world as basically hierarchical; and as a result males approach conversations as negotiations in which people try to achieve and maintain the upper hand if they can and protect themselves from others' attempts to put them down and push them around. In contrast, females are socialized to see the world as a community and to focus on their connections with others in the community. As a result females approach conversations as negotiations for closeness in which people try to seek and give confirmation and support, and to reach consensus. They try to protect themselves from others' attempts to push them away, and the end result: neither understands the other. In other words, it is important to know the meaning of communication and what is it about males and females communication style that makes them so different? Communication is the centre or the heart of intimate/close human relationship and a strong key to a successful male and female or couple relationship; and it is the foundation on which all other things are built. Communication according to Bergin (1981:1) refers to "the art, science and technology of transmitting ideas, information and 
attitudes from one person to another in order to evoke a discriminating response. Communication means the way people create and share meaning, both verbally and non verbally and the ability to communicate is one of the most essential skills individuals must master if they want to enjoy intimate or close relationships (Olson and Defrain, 2000). The ability or the willingness to communicate effectively has been found to be the most important factors in maintaining a satisfying relationship.

On the other hand, some researchers (sociologists) maintain that, common gender-related differences in communication usually cause conflict and misunderstanding between males and females. According to Olsan and Defrain (2000), there are two different styles of communication: a masculine style and a feminine style. And a better understanding of the differences between these styles will reduce some of the friction between males and females. Some researchers (Tannen, 1993, and Heaton and Blake, 1999) identify males as using an instrumental style of communication and females as using an expressive style of communication. Instrumental communication refers to having a focus on identifying goals and finding solutions. Expressive communication involves the expression of emotions and has perspective that is sensitive to how others feel. Generally, males are more interested in having rational discussions and solving problems and females are more interested in expressing emotions and feeling listened to and provided with support (Olson and Defrain, 2000).

Other differences in communication according to Tannen (1993) and Meier (1991) include females' use of rapport talk, which involves discussing similarities and matching experiences, and males' use of report talk that involves discussing knowledge and displaying skill. Infact, males and females talk differ considerably. Females usually prefer discussions about their personal lives and feelings, whereas males prefer discussions about their achievements, activities and events. There are differences in mixed-sex conversations, where 
females are more often listeners and supporters and males are more often lecturers or teachers. The explanation of these differences is attributed to the socialization process of the individual because during socialization, the games males and females play from childhood differs. For males, the game is do you respect me? And for females, the game is do you like me? (Tannen 1990 and 1994). Again, mixedsex conversation places females in a double bind, because males' style of conversation is dominant in most situations (Tannen and Aries 1997). The reason is that male style is used as the norm against which the female will be judged or evaluated, if she adopts either a male or a female style. Tannen further explains that if they speak in ways expected of females they are seen as inadequate leaders. If they speak in ways expected of leaders, they are seen as inadequate of females.

In fact, researchers have shown that males and females have different communication styles in formal and informal group meetings including school. Crawford (1995) suggests that individuals can generate males and females communication patterns or characteristics differentially. For instance, empirical research (Danielle, Roxanne, Mary, Kerry and Melanie, 2003) has shown that females are believed to use good grammar, speak politely, fluently and are soft-spoken, emotional, shy, gullible, hesitant, ingratiating and weak. While males are believed to have demanding voices, to be dominating, authoritarian, and straight to the point, blunt, forceful, boastful and to use swear words and slang. Equally in a study of feminine speech in a homogeneous gender group, Shelly (1996) describes feminine interaction with verbal characteristic distinct from masculine interaction cues such as verbal style (use of tag questions like isn't it, aren't you), posture and gaze due to status differences from the larger society.

In other words, the concept of gendered communication and interaction among individuals or group of individuals in school setting recognized differential gender manipulations in the way people speak, communicate and relate with each other. This gendered interaction involves communication skills such as effective speaking and active 
listening. These skills are employed by males and females differently in the same sex and mixed-sex schools. Studies have also shown that males and females produce and prefer different communicative style and males and females are more comfortable participating in different types of conversation. These studies were conducted in western countries within European culture. However, no documented evidence exists to suggest that studies have been carried out in the area of gender differences in communication patterns of females in single-sex and mixed-sex school within Nigerian educational research. Against this background, this study is embarked upon primarily to examine the influence of school-type on communication patterns of female students. Examining such variables would help identify the female students' dominant communication patterns and their overall influence on the individual female's socialization process with particular reference to education and schooling.

\section{Research Questions}

Two research questions guided the study which includes:

(1) What are the dominant communication patterns of females in single-sex school?

(2) What are the dominant communication patterns of females in mixed-sex school?

\section{Hypothesis}

The study hypothesized at (0.05) level of significance that school-type has no significant influence on female students' communication patterns.

\section{Significance of the Study}

This study will provide empirical data and information on the interaction between female students' communication patterns and school-type. It will provide new insight on the role of gender in conversation or interaction process of the students based on the existing cultures and dominance theories of masculine and feminine behaviours. 
It will provide data for the educators and school administrators, curriculum planners, teachers, professionals and career counsellors on the influence of school-types on the communication patterns of female students. Such information will help policy-makers in the area of female and male education and school-type which will in turn aid and enhance social adjustment in both policies and coeducation practices. Specifically, it will provide data for educational sociologists in particular, counsellors and psychologists with increased understanding of communication patterns of females in single-sex and mixed-sex schools which will help them to rehabilitate students and people with communication difficulties.

\section{Methodology}

The design used in the present study is ex-post-facto research design in which attempt was made to elicit information from students on the influence of school -type on female students' communication pattern. This study was carried out among female students in one mixed-sex and one single-sex secondary schools in Nnewi Education Zone of Anambra state.

The population for the study consisted of all the 218 senior secondary II female students in the two schools in Nnewi Education zone. Using purposive sampling approach all the 218 SSII female students made up of 132 females from single-sex school and 86 females from mixedsex schools were used from Girls' Secondary School Ozubulu and Community Secondary School Ozubulu, all in Nnewi Education zone of Anambra state which indicated that there was no sample.

An observation instrument the checklist was used for data collection to record the communication patterns of females in single-sex and mixed-sex schools, with two debate tests- Art subjects are better than science subjects and mission school is better than public school. Both face and construct validation methods were employed in standardization of the instrument. In addition using the first and second debate tests, inter-scorer reliability measure was computed 
using Kendall tan $\mathrm{t}$ coefficient of concordance to determine the internal consistency and the instrument yielded an internal reliability figure of 1.0. This implied that there was concordance in the rating of female students' communication patterns. Data collected was by participant observation approach involving the researchers and research assistants. To analyze the data collected, frequency tables, percentages and chi-square were used.

\section{Results}

The results of this study were presented according to the research questions and hypothesis of the study.

\section{Research Question 1}

What are the dominant communication patterns of female students in single-sex school?

The results as shown in table 1 showed that the dominant communication patterns of females in single-sex school are appropriate gestures, correct grammar, use of no slang, cooperative/supportive attributes, politeness, fluency, staying on topics, talkativeness, use of no tag questions, emotionality and loudness in that order. These patterns had at least $5 \%$ of the total occurrences of the female communication patterns in this two debate tests. It was discovered that the use of appropriate gestures was the most dominant communication patterns of females in single-sex school.

\section{Research Question 2}

What are the dominant communication patterns of females in mixedsex school?

The results equally revealed that the dominant communication patterns of females in mixed-sex school were use of no tag question, politeness, use of no slang, cooperative/supportive attributes, correct grammar, fluency, staying on topic, appropriate gestures talkativeness, emotionality and soft-spokenness in that order (See table 2). These were the patterns that had at least $5 \%$ of the total occurrences of the 
female communication patterns in the two debate tests in mixed-sex school. The use of no tag questions was found to be the most dominant communication patterns of females in mixed-sex school.

\section{Hypothesis:}

School-Type has no Significant Influence on Female Students

\section{Communication Patterns}

The analysis shown in table 3 revealed that the hypothesis that schooltype has no significant influence on female students communication patterns is rejected, since the calculated chi-square is greater than the $\mathrm{x}^{2}$ critical. It then implies that school-type influences female students' communication patterns significantly. It further implies that the communication patterns of female students sometimes depend on whether she is in single-sex school or mixed-sex school.

\section{Discussions}

The result of the study into the influence of school type on communication patterns of females in single-sex and mixed-sex school shows that the dominant communication patterns of females in single-sex school include: appropriate gestures, correct grammar, fluency, staying on topic, talkativeness, politeness, use of no slang, loudness, emotionality, use of no tag questions and cooperative/supportive attributes. These findings are consistent with earlier studies by Danielle, Roxanne, Mary, Kerry and Melanie (2003) and Tannen (1994). The authors maintained that some of the females' communication styles or patterns include; the use of good grammar, speaking politely, fluently, emotionally, gently, friendly use of appropriate gestures etc. Tannen (1993) and Olson and Defrain (2000) support the findings of this study that females use expressive style of communication which involves the expression of emotions and having a perspective that is sensitive to how others feel.

The findings as summarized in table 2 showed that the dominant communication patterns of females in mixed-sex school include: use of no tag questions, politeness, use of no slang, cooperative/supportive 
attributes, correct grammar, fluency, staying on topic, appropriate gestures, talkativeness, emotionality and soft spokenness. These dominant communication patterns of females in mixed-sex school namely politeness, use of no tag questions and others listed above, as revealed in the findings of this study were in concordance with the findings of (Shelly, 1996 and Tannen, (1994).

The chi-square analysis showed that school-type influences female students communication patterns significantly since the calculated chisquare 58.275 is greater than $x^{2}$ critical 32.671. This further indicates that the communication patterns of a female student sometimes depend on whether she is in a single-sex or mixed-sex schools. The finding is consistent with Shelly (1996) which noted that differences are bound to exist between genders in the same sex groups in different settings. Females in single-sex group see themselves as equal and exhibiting almost the same communication patterns during classroom interaction. While in mixed-sex group, due to power differentials and domineering nature of males, they intimidate the females, dominate and control the classroom interaction. These bring about the relegation of females to the background which in turn results to low self-esteem and low status, and affects their participation in the classroom discourse and sometimes outside the classroom.

\section{Conclusion and Recommendations}

Based on the discussions so far, it can be concluded that school-type influences female students communication patterns and that female student dominant communication patterns in single sex school include, appropriate gestures, correct grammar, politeness, fluency, staying on topic, talkativeness use of no slang, loudness, emotionality, use of no tag questions, supportive cooperative attributes while female students dominant communication patterns in mixed-sex school include: use of no tag questions, politeness, use of no slang, cooperative/supportive attributes, correct grammar, fluency, staying on topic, appropriate gestures, talkativeness, emotionality and softspokenness. In other words, the study recommends that there is need 
to incorporate discourse analytical techniques in school language curriculum, which focuses on how students can learn speech and communication patterns through exposure to different types of discourse, and also on how teachers can improve their teaching practices by investigating actual speech and language use both in an out of the classroom, since school-type had significant influence on female students communication patterns.

\section{References}

Azikiwe, U.(2001). "Gender Issues and the Universal Basic Education Programme". The Nigerian UBE Journal, 1 (2), 371-378.

Bergin, F. J. (1981). Practical communication. Britain: Pitman Publishing Limited.

Crawford, M. (1995). Talking Difference: On Gender and Language. London: Sage.

Danielle, P., Roxanne, A.D, Mary C, Kerry, L.M, and Malanie. P.(2003) "Gender, Race and Speech Style Stereotypes." Issues, 1 - 11 .

Heaton, T.B, and Blake, A.M. (1999) "Gender Differences in Determinants of Marital Disruption." Journal of Family Issues, 20, 25-46.

Keller, E. (1991). "Gender and Science." In H. Tharney (ed), Women's Studies Encyclopaedia. New York.

Meier, P. (1991). "War of Words: Women Talk about How Men and Women Talk." Minneapolis Star Tribune.

Olson, D.H., and Jefrain, J. (2000) Marriage and the Family Diversity and Strengths. U.S.A: Mayfield Publishing Company.

Pollard, M.S., and Morgan, S.P. (2002). "Emerging Parental Gender Indifference? Sex Composition of Children and the Third Birth." American Sociological Review, 67,600-613.

Shelly, R.K (1996). "Feminine Speech in Homogeneous Gender Groups." Current Research, 1 (6) 50-59.

Tannen. D. (1993). Gender and Conversational Interaction. New York: Oxford University Press. 
Tannen, D (1994). Gender and Discourse. New York: Oxford University Press.

Tannen, D. and Aries E. (1997). "Conversational Style: Do Women and Men Speak Different Language?" In M. R. Walsh (Ed), Women, Men and Gender: Ongoing Debates. New Haven, CT: Yale University Press.

Table 1: Frequency Counts and Percentages of Female Students Communication Patterns On Two Competitive Debate Tests In Single-Sex School.

\begin{tabular}{|l|l|l|l|l|}
\hline $\begin{array}{l}\text { Communication } \\
\text { patterns }\end{array}$ & Test I & Test II & Total & $\begin{array}{l}\text { Percentage } \\
(\%)\end{array}$ \\
\hline Polite & 100 & 132 & 232 & 8.0 \\
\hline Impolite & 5 & 15 & 20 & 0.69 \\
\hline Talkative & 96 & 92 & 188 & 6.5 \\
\hline Quiet & 36 & 40 & 76 & 2.6 \\
\hline Loud & 78 & 78 & 156 & 5.4 \\
\hline Soft spoken & 53 & 54 & 107 & 3.7 \\
\hline Correct grammar & 123 & 120 & 243 & 8.4 \\
\hline Incorrect grammar & 22 & 19 & 41 & 1.4 \\
\hline Uses slang & 15 & 15 & 30 & 1.0 \\
\hline No slang & 117 & 117 & 234 & 8.1 \\
\hline Fluent & 107 & 107 & 214 & 7.4 \\
\hline Not fluent & 24 & 24 & 48 & 1.7 \\
\hline Appropriate gestures & 127 & 127 & 254 & 8.8 \\
\hline Exaggerated gestures & 5 & 5 & 10 & 0.34 \\
\hline Uses tag questions & 43 & 42 & 88 & 2.9 \\
\hline No tag questions & 87 & 86 & 173 & 6.0 \\
\hline Emotional & 81 & 80 & 161 & 5.6 \\
\hline Unemotional & 52 & 51 & 103 & 3.6 \\
\hline Loses train of thought & 34 & 25 & 59 & 2.0 \\
\hline Stays on topic & 108 & 99 & 207 & 7.1 \\
\hline Cooperatively/ supportive & 117 & 117 & 234 & 8.1 \\
\hline Argumentative & 17 & 16 & 33 & 1.1 \\
\hline Total & 1400 & 1500 & 2900 & 100 \\
\hline & & & & \\
\hline
\end{tabular}


Table 2: Frequency Counts and Percentages of Female Students Communication Patterns on Two Competitive Debate Tests in MixedSex School.

\begin{tabular}{|l|l|l|l|l|}
\hline $\begin{array}{l}\text { Communication } \\
\text { patterns }\end{array}$ & Test I & Test II & Total & Percentages (\%) \\
\hline Polite & 78 & 77 & 155 & 8.3 \\
\hline Impolite & 8 & 9 & 17 & 0.9 \\
\hline Talkative & 62 & 60 & 122 & 6.6 \\
\hline Quiet & 23 & 26 & 49 & 2.6 \\
\hline Loud & 35 & 33 & 68 & 3.7 \\
\hline Soft-spoken & 53 & 48 & 101 & 5.4 \\
\hline Correct grammar & 74 & 63 & 137 & 7.4 \\
\hline Incorrect grammar & 21 & 14 & 35 & 1.9 \\
\hline Uses slang & 12 & 12 & 24 & 1.3 \\
\hline No slang & 75 & 75 & 150 & 8.1 \\
\hline Fluent & 68 & 66 & 134 & 7.2 \\
\hline Not fluent & 21 & 21 & 42 & 2.3 \\
\hline Appropriate gestures & 65 & 62 & 127 & 6.8 \\
\hline Exaggerated gestures & 5 & 2 & 7 & 0.4 \\
\hline Uses tag questions & 10 & 8 & 18 & 1.0 \\
\hline No tag questions & 79 & 77 & 156 & 8.4 \\
\hline Emotional & 58 & 45 & 103 & 5.5 \\
\hline Unemotional & 41 & 28 & 69 & 3.7 \\
\hline Loses train of thought & 30 & 10 & 40 & 2.2 \\
\hline Stays on topic & 75 & 56 & 131 & 7.1 \\
\hline Cooperative/supportive & 75 & 69 & 144 & 7.8 \\
\hline Argumentative & 17 & 11 & 28 & 1.5 \\
\hline Total & 925 & 872 & 1857 & 100 \\
\hline & & & & \\
\hline
\end{tabular}


Table 3: Summary of Chi-Square Analysis of the Influence of SchoolType on Female Students Communication Patterns.

\begin{tabular}{|l|l|l|l|}
\hline & \multicolumn{2}{|l|}{ School-type } & Total \\
\hline Communication patterns & $\begin{array}{c}\text { Single-sex } \\
\text { school }\end{array}$ & $\begin{array}{c}\text { Mixed-sex } \\
\text { school }\end{array}$ & \\
\hline Polite & $232(236.2)$ & $155(150.85)$ & 387 \\
\hline Impolite & $20(22.58)$ & $17(14.4)$ & 37 \\
\hline Talkative & $188(189.22)$ & $122(120.8)$ & 310 \\
\hline Quiet & $76(76.3)$ & $49(48.7)$ & 125 \\
\hline Loud & $156(136.7)$ & $68(87.3)$ & 224 \\
\hline Soft-spoken & $107(127)$ & $101(81.1)$ & 208 \\
\hline Correct grammar & $243(232)$ & $137(148.1)$ & 380 \\
\hline Incorrect grammar & $41(46.39)$ & $35(296)$ & 76 \\
\hline Uses slang & $30(32.96)$ & $24(21)$ & 54 \\
\hline No slang & $234(234.4)$ & $150(149.68)$ & 384 \\
\hline Fluent & $214(212.4)$ & $134(135.6)$ & 348 \\
\hline Not fluent & $48(54.9)$ & $42(35.1)$ & 90 \\
\hline Appropriate gestures & $254(232.6)$ & $127(148.5)$ & 381 \\
\hline Exaggerated gestures & $10(10.4)$ & $7(6.6)$ & 17 \\
\hline Uses tag questions & $85(62.87)$ & $18(40.1)$ & 103 \\
\hline No tag questions & $173(200.8)$ & $156(128.24)$ & 329 \\
\hline Emotional & $161(161.1)$ & $103(102.9)$ & 264 \\
\hline Unemotional & $103(105)$ & $69(67.05)$ & 172 \\
\hline Loses train of thought & $59(60.4)$ & $40(38.6)$ & 99 \\
\hline Stays on topic & $207(206.3)$ & $131(131.75)$ & 338 \\
\hline Cooperative/supportive & $234(230.7)$ & $144(147.3)$ & 378 \\
\hline Argumentative & $33(37.2)$ & $28(24)$ & 61 \\
\hline Total & 2908 & 1857 & 4764 \\
\hline $\mathrm{X}^{2}$ Critical $) 32.671$ & \\
\hline $\mathrm{X}=0.05)$. & & \\
\hline
\end{tabular}

